\title{
The effects of railway investments in a polycentric city: a comparison of competitive and segmented land markets
}

\author{
Ghebreegziabiher Debrezion, Eric Pels, Piet Rietveld \\ Department of Spatial Economics, Free University, De Boelalaan 1105, 1081 HV Amsterdam, \\ The Netherlands; e-mail: gdebrezion@feweb.vu.nl, apels@feweb.vu.nl, prietveld@feweb.vu.nl \\ Received 21 October 2005; in revised form 17 May 2006
}

\begin{abstract}
The paper analyzes the effect of railway investment on land prices and land use in a polycentric city under various regulatory regimes of land markets. The introduction of a fast mode of transport (train), accessible in discrete locations, leads to an increase in city size. The stations of the fast mode induce dense residential settlements in their vicinity. As a result, the average residential and commercial land rents increase in both competitive and segmented land-market situations, compared with the unimodal transport case. When rail investments serve only one particular centre, this leads to the growth of the advantaged centre at the expense of the other centre. An investment in the fast mode results in city growth and an increase in rent receipts. However, the effect of the investment for individual centres and their corresponding residential areas depends on the underlying land-market conditions. Restrictions on commercial land use lead to increases in commercial rents, but this is more than offset by the decrease in residential land rents.
\end{abstract}

\section{Introduction}

The car has gradually become the dominant transport mode in most cities in developed countries. However, there still are cities, such as London, Paris, and New York, where a large proportion of the workers use public transport. Therefore, to make a proper analysis of land and labour markets in such cities, both transport modes should be considered. Many cities started with a clear monocentric structure. During the course of time, however, a gradual deconcentration process took place, leading to the decreasing dominance of the original centre. But, in some cases, edge cities have developed, implying the emergence of additional centres of commercial activity in a metropolitan area (Garreau, 1988). In other cases, the gradual growth of small and medium-sized cities led to the evolution of large metropolitan areas consisting of overlapping urban areas that were formerly independent. In both these cases of city evolution, the original monocentric urban model no longer applies. This paper sets out to study both phenomena in an urban model which deals with the combination of multiple transport modes and multiple centres of economic activity.

In relation to the type of centre and model of transport assumptions, we can logically distinguish four categories of urban models: monocentric-unimodal transport; monocentric-multimodal transport; polycentric-unimodal transport; and polycentric-multimodal transport models. Most of the literature is in line with the first category, although recently, more and more studies that use the polycentric city setting have appeared. But they are still dominated by the unimodal transport assumption. This paper can be seen as a study in the last of the four categories mentioned above. It deals with an urban model of two centres and two transport modes. The goal of this paper is to develop an urban model with an emphasis on the impact of investment in transportation on the real-estate market. Thus, this paper assesses the effect of investment in rail on the spatial rent structure. Three levels of railway investments are compared: no rail investment, partial railway investment where only one of the two centres is connected by railway, and a complete railway investment in which both centres are connected by railway. Moreover, this helps to assess the effects of an additional transport system 
(in this case, rail) on urban growth in general, and the growth of particular subcentres. In addition, this paper assesses the effect of partial railway investment on the competitive positions of centres within the city. Finally, the paper addresses an institutional issue: the extent to which a regulated land market would lead to different results. In particular, we address the question of which institutional setting (competitive versus segmented market) leads to the highest rent increases owing to investments in rail infrastructure. For each of the three levels of railway transport investment we consider three situations concerning the land-market regimes in the centres: a competitive land market in both centres, a segmented land market imposed in both centres, and a mixed land market in which one centre has a competitive land market land while segmentation is imposed in the other.

In subsequent sections we briefly discuss the relevant literature (section 2), the specification of our model (section 3), and the equilibrium conditions of the model (section 4). We introduce the model for alternative land markets in section 5. The model simulation and results are discussed in section 6 . Finally, we suggest directions for future research (section 7).

\section{Literature review}

The relation between land values and proximity of land to employment centres has been addressed extensively in the literature. The monocentric circular city has received most attention. However, in many parts of the world, especially in Western Europe, Japan, and the US, metropolitan areas are increasingly assuming polycentric structures. The Randstad in Holland, Rhine-Ruhr metropolitan area in Germany, the Flemish Diamond in Belgium, the Glasgow - Edinburgh region in the UK, the Padua-TrevisoVenice region in Italy, Southern California in the US, and the Kansai area in Japan are probably the most frequently mentioned polycentric structures (Batten, 1995; Dieleman and Faludi, 1998; Musterd and van Zelm, 2001; van der Wusten and Faludi, 1992). But, even though polycentric urbanization started earlier in Europe than in the US, its pace was slowed in Europe as a result of conservative urban policies.

A common starting point in the literature is that transportation is the prime factor in shaping the urban structure (Clark, 1958; Clark and Kuijpers-Linde, 1994). Besides changes on the transportation side, changes on the production side (agglomeration and productivity effects) are responsible for determining location patterns and thus shaping the urban economy (Glaeser and Kahn, 2003). Fujita et al (1999) theoretically explained the effects of agglomeration on the optimal location of firms in relation to the location of a historic centre. In a linear city of unit length, the optimal location of a new plant will be in the historic centre for a wide range of cases. Nevertheless, at times, the optimal location of the plant can be different from the historic centre. The trade-off between agglomeration effects and transportation costs explains the coexistence of multiple centres in a city. Modarres (2003) found for Los Angeles County that subcentres contain one third of the county's employment. However, the transit network structure appears to serve these subcentres inadequately. This shows that in this case the formation of a polycentric urban structure was not in response to the development of public transit in the first place. However, the increasing use of private cars is believed to be instrumental in shaping the present dispersed urban structure (Clark, 1958; Glaeser and Kahn, 2003). In addition to the use of cars, Sivitanidou (1997) showed that the recent information revolution is also contributing towards the weakening of spatial links between commercial activities and large business locations, thereby leading to increasingly dispersed business locations.

Even though polycentricity simply implies the presence of multiple centres in an urban area, there is no proper identification procedure (Anas et al, 1998). For practical 
purposes, areas can be treated as centres in terms of variables such as employment density, population (residential) density, property values, and travel patterns. Several authors have tried to propose ways of identifying centres in cities by both parametric and nonparametric methods. However, these still remain essentially subjective. The main methods used to identify subcentres are: the residual method of McDonald (1989); the employment density cutoff method of Giuliano and Small (1991); and the employment-smoothing estimation procedure of Craig and $\mathrm{Ng}$ (2001). Later, McMillen (2001) developed a two-stage centre-identification procedure, which incorporates concepts of McDonald, and Craig and $\mathrm{Ng}$. In the first stage, candidate centres are identified through the analysis of the residuals of a smoothed employment-density function. The second stage assesses the significance of the identified centres in influencing local employment densities. This reflects the definition that centres are sites which result in a significant rise in employment densities after controlling for the historic centre (the CBD). Apart from calculating an employment-density indicator, Musterd and van Zelm (2001) discussed various ways to define a polycentric city structure. Both spatial structure and the existence of intricate network-type interactions should be present before an urban area is considered to be a polycentric unit.

Several studies have addressed the effect of urban spatial structure on property values. This will also be the main focus of this paper, which attempts to answer the question: how does the polycentricity of an urban area shape the land-rent structure? The value of a centre is capitalized in the form of land rents. In addition to the predetermined centre in the urban models, other studies, without explicitly referring to the centre(s), have concluded that the rent gradient peaks around the most valuable location in the urban spatial structure. Indirectly, these peaks are also used to identify the centre(s) of the city. However, in this sense, the monocentric assumption is in reality a very simplistic assumption. Therefore, over the years, attempts have been made to develop urban models in the context of polycentric situations (prespecified and non-prespecified locations).

A comprehensive general equilibrium polycentric urban model was developed by Anas and Kim (1996). Without scale economies of shopping, production is dispersed in the city with rent, wage, and commodity price and density gradients peaking in the centre of the space. One of the models on property values in a bicentric city was developed by Sivitanidou and Wheaton (1992). Special attention was given to the centres' production cost difference and commercial land-market regulation. The main finding of the paper was that cost advantages are capitalized in commercial land rent and wages (and wages in their turn, in residential land rents). The level of capitalization of production cost advantages in commercial land rent becomes higher in the regulated commercial land market compared with the competitive market. In this paper we extend Sivitanidou and Wheaton's (1992) model by introducing an additional mode of transport (rail: a fast mode with discrete access points) running through the bicentric linear open city. In the model, households and firms interact via the exchange of labour and wages. The differences between our model and that of Sivitanidou and Wheaton (1992) concern aspects such as: the introduction of a second transport mode; endogenous land consumption by households; endogenous density of settlements; and endogenous wages for the two centres.

\section{The structure of the model}

\subsection{Bicentric - bimodal urban structure: model description}

In this section we introduce an equilibrium urban land-use model. The city in our model has two (area-occupying) centres, that both function as employment and production centres. Labour is employed from households living in the residential areas of the city. 
Homogeneous households arrive at either of the two centres and supply labour. The inputs in the production process constitute labour and commercial floor space. In the production process of the centres, we assume a fixed ratio between labour and floor space. Floor space is prepared in a cost-minimizing fashion from land rented at the commercial land-rent rate and capital rented at some market rent of capital. The output follows a fixed-proportion, constant-returns-to-scale technology and is exported at a given price in a fully competitive market.

The households are assumed to have a well-behaved utility function with residential land and nonland consumption goods as its components. By travelling to one of the employment centres, households acquire an endogenously given wage. No other income sources are considered. The residential land rent has a bid nature. The price of nonland consumption goods is taken as a numéraire (unity). All commercial and residential rents are absorbed by absentee landowners. We further assume that the city we deal with is open: households can freely migrate into or out of the city. The households enjoy the national utility level, $u$, which is bounded from below by the supreme utility level (a level of utility that guarantees the existence of the city) (Fujita, 1989). Thus, all households in the city enjoy a given utility level that is equivalent to the level of utility enjoyed by the households outside the city in the economy.

Two modes of transport operate in the open city: a 'slow' mode (car) that is accessible from anywhere in the city, and a 'fast' mode (train) accessible from certain fixed stations. The distinction between the 'slow' and 'fast' modes relates not only to the time cost of transportation, but also to the generalized transportation cost structure. The fast mode results in some sort of cost saving, and is thus termed 'fast'. Thus, the cost per distance unit of transportation for the fast mode (train) is lower than that of the slow mode. In our linear city model, as well as at the centres, we assume three additional stations at a distance of $\frac{1}{2} b$ miles from the edges of the centres (see figure 1 ). We assume transportation costs inside the centres to be zero. The households use the slow or fast mode or a combination of both in cost-minimizing fashion to reach the centre, where they earn net income (wages minus transport costs). There are three possible situations. A resident at the location of a railway station uses only the railway mode. Households at the location near a railway station use a car to the station and transfer to rail for commuting to the employment centre. Workers at locations near employment centres use only a car for commuting.

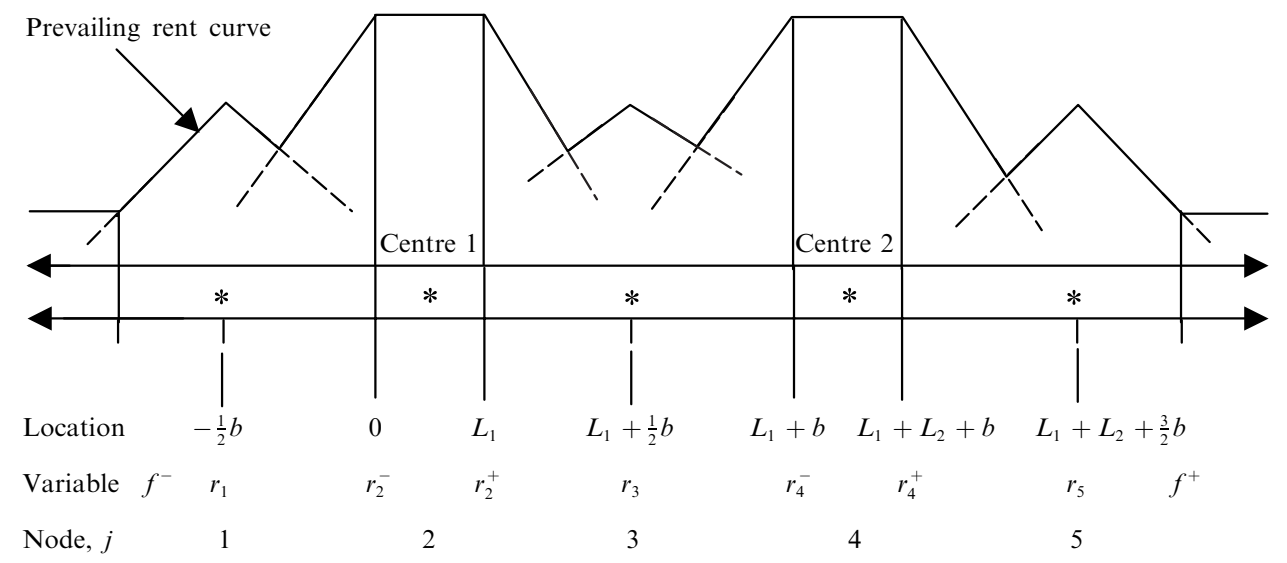

Figure 1. Layout of linear city with two commercial centres, each with its own railway station $\left(^{*}\right)$ and three additional railway stations. 
The exogenous parameters of the model are the following. On the consumer side we have the national utility level, price of nonland consumption goods, and transportation costs of the two modes. On the producer side we have the floor-space requirement per worker, and the cost of capital. Lastly, for the spatial structure of the city we have the width of the city and the distance between the nodes. The values of the exogenous variables used in the simulation are given below in table 3 . Analysis is provided for two regulatory alternatives for land-market situations: competitive and segmented markets.

\subsection{Notation and definition of variables}

The general layout of the city structure is depicted in figure 1. The two centres occupy a significant amount of land for commercial purposes in the urban area. The two centres are $b$ distance units away from the edges. The left edge of centre 1 is taken as the origin of the linear city. In figure 1 the second row gives the variable representing the location of some critical points in the linear city such as the fringes of the city $\left(f^{-}\right.$and $\left.f^{+}\right)$, the edges of the centres $\left(r_{2}^{-}\right.$and $r_{2}^{+}$for centre 1 , and $r_{4}^{-}$and $r_{4}^{+}$for centre 2$)$, and the

Table 1. Model variables.

\section{Variable Description}

\begin{tabular}{|c|c|}
\hline$I$ & The set of employment and production centres $I=\{1,2\}$ \\
\hline$J$ & The set of transport nodes $J=\{1,2, \ldots, 5\}$, where $I \subseteq J$ \\
\hline$r$ & A variable location in one-dimensional space \\
\hline$r_{j}$ & Location of node $j, j \in J$, in one-dimensional continuous space \\
\hline$u$ & Utility level \\
\hline$w_{i}$ & Wage at centre $i, i \in I$ \\
\hline$Y_{i}^{*}$ & Artificial income at node $j, j \in J$ \\
\hline$R^{\mathrm{A}}$ & Rent for agricultural land (the basic land rent) \\
\hline$R_{i}^{\mathrm{C}}$ & Commercial land rent at centre $i, i \in I$ \\
\hline$r_{\mathrm{c}}$ & Rent of capital $\left(\$\right.$ per $\left.\mathrm{ft}^{2}\right)$ \\
\hline$R_{i}^{\mathrm{F}}$ & Rent for floor space at centre $i, i \in I$ \\
\hline$\Psi_{j}(r, u)$ & $\begin{array}{l}\text { A function of residential land bid-rent corresponding to node } j \in J \text { at location } r \\
\text { and } u \text { level of utility }\end{array}$ \\
\hline $\mathrm{R}^{\mathrm{R}}(r, u)$ & $\begin{array}{l}\text { A function of prevailing residential rent per unit lot size of land at location } r \text { for } \\
\text { utility level } u\end{array}$ \\
\hline $\mathrm{S}(r, u)$ & $\begin{array}{l}\text { A function of size of residential land consumed by household at location } r \text {, the } \\
\max \text { bid lot size }\end{array}$ \\
\hline $\mathrm{Z}(r, u)$ & $\begin{array}{l}\text { A function of nonland goods consumed at location } r \text { (taken as numéraire with unit } \\
\text { price) }\end{array}$ \\
\hline $\mathrm{U}(z, s)$ & Utility as a function of $z$ level of nonland goods and $s$ level of land consumed \\
\hline & Transportation cost per unit distance for the slow mode \\
\hline$k_{\mathrm{f}}$ & Transportation cost per unit distance for the fast mode \\
\hline $\mathrm{T}(r)$ & Transportation cost function from location $r$ to the destination centre (node) \\
\hline$N_{i}$ & Number of employees at centre $i, i \in I$ \\
\hline$Q_{i}$ & Floor space at centre $i, i \in I$ \\
\hline$L_{i}$ & Area of commercial land at centre $i$ \\
\hline$K_{i}$ & Amount of capital employed at centre $i, i \in I$ \\
\hline$a_{\mathrm{s}}$ & Floor space per worker ratio $\left(Q s_{i} / N_{i}\right), i \in I$ \\
\hline$E_{i}$ & Other exogenous costs per worker in centre $i$ \\
\hline$A$ & Production cost advantage for centre $1\left(=E_{2}-E_{1}\right)$ \\
\hline$P$ & Productivity per worker (units/worker) \\
\hline $1(r, u)$ & $\begin{array}{l}\text { Distribution of land in the city. In the linear constant unit the width of the city } \\
\text { is given by } 1(r, u)=1\end{array}$ \\
\hline$\rho(r, u)$ & Density of households of a city at location $r$, corresponding to level of utility $u$ \\
\hline & Total number of households in the city \\
\hline$p$ & Price of production output \\
\hline$l^{\mathrm{R}}$ & Land reserved for commercial use \\
\hline
\end{tabular}


location of railway stations $\left(r_{1}, r_{3}\right.$, and $\left.r_{5}\right) . L_{1}$ and $L_{2}$ represent the sizes of the two centres. According to the land-market assumptions, they are exogenous to the model or are endogenously determined in the model. This is dealt with in detail in the next section. Table 1 introduces the variables and notation used in the next section to formulate the model. These variables are discussed in more detail below when the model details are explained.

\section{Model details}

\subsection{Household behaviour: utility maximization}

Besides the agricultural land use that starts at the outermost fringes of the city, urban land is devoted to residential and commercial use. The assumption of a land market without any imperfections guarantees that commercial land rent always outbids residential land rent in the employment centres. For residential land use, the trade-off between transport costs and other consumption opportunities leads to a downwardsloping bid-rent curve from the edge of the centres. Thus, the land-rent curve is an envelope of the curves, as depicted in figure 1.

We start with the derivation of the residential bid-rent function. The bid rent is defined as the maximum rent per unit of land that a household, at a location $r$, which travels to a specified employment centre to get an income $Y$, can pay while achieving a certain utility level $u$. The bid-rent function in the city therefore is a function of the distance and the utility level enjoyed by the households (Fujita, 1989), which can be written as:

$$
\Psi(r, u)=\max _{z, s}\left[\frac{Y-\mathrm{T}(r)-z}{s} \mid \mathrm{U}(z, s)=u\right],
$$

where $\Psi(r, u)$ is the residential bid-land-rent function, for a household at location $r$ enjoying a given exogenous level of utility $u \mathrm{U}(z, s)$ is the utility function, where $z$ is the composite consumption good of the household that has a unit price, and $s$ is the landlot size per household. The household incurs transportation costs $\mathrm{T}(r)$ which is a function of the location $r$ in reference to the location of the employment centre, and receives a level of income $Y$.

Equation (1) can be rewritten by expressing the amount of composite consumption goods of the household in terms of lot size of land and utility:

$$
\Psi(r, u)=\max _{s}\left[\frac{Y-\mathrm{T}(r)-\mathrm{Z}(s, u)}{s}\right] .
$$

For a fixed utility level, $u$, the first-order condition for maximizing the right-hand side of equation (2) occurs at the point at which the marginal change of the function with respect to $s$ is zero. This leads to the relation:

$$
-\frac{\partial \mathrm{Z}(s, u)}{\partial s}=\frac{Y-\mathrm{T}(r)-\mathrm{Z}(s, u)}{s}
$$

At the optimal choice of $s$ the right-hand side of equation (3) equals the bid rent $\Psi(r, u)$ :

$$
-\frac{\partial Z(s, u)}{\partial s}=\Psi(r, u)
$$

This means that a marginal decrease in the consumption of nonland composite consumption goods due to an increase in the consumption of lot size of land is equal to the bid rent of land. 
For simplicity and ease of derivation, we assume that the utility function of the household has the following functional form:

$$
\mathrm{U}(z, s)=\alpha \ln z+\beta \ln s, \quad \alpha+\beta=1 .
$$

It can be shown that $\mathrm{Z}(s, u)=s^{-\beta / \alpha} \exp (u / \alpha)$. By solving the maximization problem in equation (2) using the condition in equation (3), we can the derive the following residential bid-rent function (Fujita, 1989, page 322):

$$
\Psi(r, u)=\alpha^{\alpha / \beta} \beta[Y-\mathrm{T}(r)]^{1 / \beta} \exp \left(-\frac{u}{\beta}\right) .
$$

Given the bid-rent level for the price of land, the lot-size level that optimizes utility is given as:

$$
\mathrm{S}(r, u)=\frac{\beta[Y-\mathrm{T}(r)]}{\Psi(r, u)}=\alpha^{-\alpha / \beta}[Y-\mathrm{T}(r)]^{\alpha / \beta} \exp \left(\frac{u}{\beta}\right) .
$$

The density of settlement $(\rho)$ is given by the inverse of the maximum bid-lot size, and gives the number of households per unit lot-size area:

$$
\rho(r, u)=\frac{1}{\mathrm{~S}(r, u)} .
$$

\subsubsection{Income at nodes}

The above bid-rent function can easily be applied in the case of a monocentric unimodal city. However, in the present case with two modes and two commercial centres some further steps are needed. First, the household's transport cost curve, T( $r)$, has to be derived from the modal choice model. Second, the income level, $Y$, is no longer unique since wages may be different in the two nodes. As will be explained below, in order to keep the models tractable we introduce the transport costs related to the fast mode in the income variables.

Households travel to the employment centre that maximizes their net income. Because of the cost-saving nature of the fast mode (rail) we observe three possible ways of commuting to the employment centres. First, households residing at the stations will directly use the fast mode to commute to the employment centre, which maximizes their net income. Second, households residing around the stations will use the slow mode (car) to reach the stations and then take the fast mode to the employment centre, which maximizes their net income. Third, households residing around the employment centres will use the slow mode to commute directly to the employment centre. Thus, the slow mode has two types of destination: a transfer station or a real employment centre.

We now turn to the income levels earned in the various nodes. For people working in the two commercial centres $j=2$ and $j=4$ and travelling by car to these centres, the income equals the pertaining wage levels $w_{1}$ and $w_{2}{ }^{(1)}$ In order to relate the bid-rent analysis to our multinodal model, we introduce a pseudo-income variable for the other workers. First, we consider stations 1, 3, and 5 as pseudo-centres with zero production. A pseudo-income is then attached to these pseudo-centres. These are equal to the net income that households residing at these centres get by commuting to the employment centres that maximizes their net income using the fast mode. Thus, we extend this income definition over all nodes (railway stations and employment centres) as given by

(1) A slightly more general formulation would allow that one of the commercial centres does not materialize because productivity is too low compared with the other node. This can easily be taken on board in the present model formulation, but we decided not to do this because it would lead to more complex model formulations without adding substantial insights. 
equation (9). The introduction of this pseudo-income variable helps to keep the model simple by internalizing the transport costs related to the fast mode in the income variable. We use the term 'artificial income' for the pseudo-income attached to each of the nodes $\left(Y_{j}^{*}\right)$, and it is defined as follows:

$$
Y_{j}^{*}=\max _{i}\left[w_{i}-\mathrm{T}_{\mathrm{f}}\left(r_{j i}\right)\right], \quad j \in J, \quad i \in I,
$$

where $\mathrm{T}_{\mathrm{f}}\left(r_{j i}\right)$ is the transportation cost from node $j$ to centre $i$ by the fast mode. In our analysis we adopt the linear transportation cost function $\mathrm{T}_{\mathrm{f}}\left(r_{j i}\right)=k_{\mathrm{f}}\left\|r_{i}-r_{j}\right\|$. Thus, the artificial income at node $j$ equals the wage in the commercial centre on which it is oriented minus the transport costs to get there by fast mode. The equality of the artificial income of the two centres in the city with the real wages offered in the corresponding centres $\left(Y_{2}^{*}=w_{1}\right.$, and $\left.Y_{4}^{*}=w_{2}\right)$ represents the coexistence of the centres as both production and employment centres. However, if one of the artificial incomes is higher than the real wages offered at the corresponding centre, this implies that the centre ceases to be a production centre. This means that this centre is dominated by the other centre: it serves as a mere transfer node to the dominant centre.

\subsubsection{Residential land rent}

Given the income level attached to each of the nodes in the city, we can safely assume that each node faces a downward-sloping residential bid-rent curve. It is a function of the utility level enjoyed by the households and the distance to the node. Households travel by the slow mode (car) to one of the nodes to work or make a transfer to the fast mode (train) depending on the nature of the node. If the node is an employment centre, households use the slow mode to reach the centre directly. In our model the two employment centres are indexed by $j=2$ and $j=4$ in the set of nodes. If the node is a railway station, households use the slow mode to reach the railway station and continue their trip to the employment centre by train. In the set of nodes the transfer stations are indexed by $j=\{1,3,5\}$ (see figure 1). Generally, there are two distances involved. The first is the distance from the transfer railway station to the employment centre which is internalized in determining the income corresponding to the nodes. The second distance relates to the distance between the location of the households' residence and the nodes. We assume that the transportation cost by the slow mode is proportional to distance. Substituting the artificial income level at the nodes and the transportation cost of reaching the nodes by the slow mode in equations (7), (8), and (9) gives the residential bid rent, maximum bid-lot size, and settlement-density functions corresponding to each of the nodes:

$$
\begin{array}{ll}
\Psi_{j}(r, u)=\alpha^{\alpha / \beta} \beta\left(Y_{j}^{*}-k_{\mathrm{s}}\left\|r_{j}-r\right\|\right)^{1 / \beta} \exp \left(-\frac{u}{\beta}\right), & j \in\{1,2, \ldots, 5\}, \\
\mathrm{S}_{j}(r, u)=\frac{\beta\left(Y_{j}^{*}-k_{\mathrm{s}}\left\|r_{j}-r\right\|\right)}{\Psi_{j}(r, u)}, & j \in\{1,2, \ldots, 5\}, \\
\rho_{j}(r, u)=\frac{1}{\mathrm{~S}_{j}(r, u)}, & j \in\{1,2, \ldots, 5\} .
\end{array}
$$

The residential bid rent, residential lot size, and settlement densities are defined only in the residential areas of the city. Due to the bidding nature of rent, the prevailing land rent at the residential areas of the city is the maximum of the rent curves corresponding 
to each of the transport nodes in the linear city.

$$
\begin{array}{ll}
R^{\mathrm{R}}(r, u)=\max _{j}\left[\Psi_{j}(r, u)\right], & j \in\{1,2, \ldots, 5\}, \\
\mathrm{S}(r, u)=\min _{j}\left[\mathrm{~S}_{j}(r, u)\right], & j \in\{1,2, \ldots, 5\}, \\
\rho(r, u)=\max _{j}\left[\rho_{j}(r, u)\right], & j \in\{1,2, \ldots, 5\} .
\end{array}
$$

\subsubsection{Commercial land rent}

In the production process of the firm(s) operating at the employment centre, land is one of the inputs in the production of floor space. Because transportation costs inside the centre are assumed to be zero, ${ }^{(2)}$ a uniform land rent for commercial use is obtained. This assumption is not unnatural. In most urban models the transportation cost inside the CBD is ignored. Besides, the size of the CBD is usually rather small compared with the rest of the metropolitan area. A consequence of the assumption is that households take the edge of the centres as a reference for the location of the employment centres. ${ }^{(3)}$ At the edge of the centres the commercial land-rent curve takes over. This situation is guaranteed both under competitive and under segmented landmarket assumptions as will be explained in section 5. In the competitive land-market situation the commercial land rent outbids the residential land-bid-rent curve. At the edge of the centres the commercial land rents are equal to the corresponding residential land rents. On the other hand, the segmented market situation guarantees that the commercial land rent takes over whether it outbids the residential land rent or not. The commercial land-rent function is derived from the producer behaviour in section 4.2.

\subsubsection{Prevailing land rent and land use}

In the model we distinguish three types of land use: commercial, residential, and agriculture. The agricultural land rent is given exogenously to the model. The uniform commercial land rent outbids the downward-sloping residential rent curve which starts at the edge of the centre. Thus, the prevailing rent curve at any point in space is the maximum of the residential, commercial, and agriculture land rents, which can be written as:

$$
\mathrm{R}(r)=\max _{i \in I}\left[R^{\mathrm{R}}(r, u), R_{i}^{\mathrm{C}}, R^{\mathrm{A}}\right] .
$$

\subsection{Producer behaviour: cost minimization}

On the production side, the model incorporates the assumption of Sivitanidou and Wheaton (1992), in which the two centres make products that utilize labour and floor space and that are sold outside the city. Floor space at the centres $\left(Q_{i}\right)$ is

(2) It would also be possible to consider transportation cost inside the centres. This would strongly complicate the formulation of the model since it would lead to wage levels that depend on the location of work within the cluster. Workers at the fringe of the commercial area (that is, those who travel by car) would earn (slightly) less than workers working closer to its centre because the latter would need compensation for the extra transport costs. Along similar lines the workers who travel by train and whose jobs are close to the central station would have lower wages than the workers who have to walk a certain distance from the station to the workplace. This would lead to a wage gradient in the commercial area that is low at the fringes and in the centre, and that has peaks in between. This would imply that the rent in the commercial area would not be constant, and this means that the densities would also not be constant: high densities would be expected at the centre and at the fringes, and lower values would be expected in between. Although such refinements would be interesting to study, we feel they would substantially complicate the analysis without major benefits in terms of additional insights on the themes studied.

(3) In fact, their bid curve within the commercial centre would be flat given the fact that transport costs within the centre are zero. 
produced by making use of capital $\left(K_{i}\right)$ and land $\left(L_{i}\right)$ with a constant-returns-to-scale Cobb-Douglas production function, as given below:

$$
Q_{i}=K^{\delta} L^{1-\delta} \text {. }
$$

Centres are assumed to have constant floor-space demand per worker $\left(a_{\mathrm{s}}=Q_{i} / N_{i}\right)$. Thus, given the price of capital $\left(r_{\mathrm{c}}\right)$, rent for floor space is given by:

$$
R_{i}^{\mathrm{F}}=\frac{R_{i}^{\mathrm{C}} L_{i}+r_{\mathrm{c}} K_{i}}{a_{\mathrm{s}} N_{i}}, \quad i \in I,
$$

where $a_{\mathrm{s}} N_{i}$ is the total demand for floor space, and the numerator is the total expenditure in floor space. The cost-minimizing input bundle for floor space is given by:

$$
\begin{aligned}
& K_{i}=a_{\mathrm{s}} N_{i}\left[\frac{\delta R_{i}^{\mathrm{C}}}{(1-\delta) r_{\mathrm{c}}}\right]^{1-\delta}, \quad i \in I, \\
& L_{i}=a_{\mathrm{s}} N_{i}\left[\frac{(1-\delta) r_{\mathrm{c}}}{\delta R_{i}^{\mathrm{C}}}\right]^{\delta}, \quad i \in I .
\end{aligned}
$$

Therefore, the long-run cost-minimizing floor-space rent is:

$$
R_{i}^{\mathrm{F}}=r_{\mathrm{c}}^{\delta} \delta^{-\delta}(1-\delta)^{(\delta-1)} R_{i}^{\mathrm{C}(1-\delta)}, \quad i \in I .
$$

The total costs of production at each of the centres are the sum of wage, rent of floor space, and some other exogenous production costs. The other exogenous production costs may include all costs different from those already discussed (labour, land, and capital). Examples are locally varying tax payments, differences in local facilities, differences in costs of transport to the outside market, or agglomeration advantages and costs associated with the use of local public services. The difference between the exogenous production costs of the two centres reflects the level of cost advantage one centre has over the other. The situation where $E_{2}-E_{1}>0$, indicates that centre 1 has a cost advantage over centre 2. Centres operate at a zero profit level. Productivity per worker $(P)$ is assumed to be the same in both centres. The output of both centres is exported to a national market at a unit price. Wages in both centres are determined endogenously by the model.

$$
\begin{aligned}
& P-E_{1}-w_{1}-R_{1}^{\mathrm{F}} a_{\mathrm{s}}=0, \\
& P-E_{2}-w_{2}-R_{2}^{\mathrm{F}} a_{\mathrm{s}}=0 .
\end{aligned}
$$

In other words, the production equilibrium condition between the centres thus states that the costs per worker at each of the centres should be equal:

$$
w_{1}+R_{1}^{\mathrm{F}} a_{\mathrm{s}}+E_{1}=w_{2}+R_{2}^{\mathrm{F}} a_{\mathrm{s}}+E_{2} .
$$

The main theme of the paper by Sivitanidou and Wheaton (1992) was the effect of relative cost advantages on the spatial rent structures. In order to focus on the effect of railway investment on the spatial rent structure, our discussion of the simulation assumes the exogenous cost component.

\subsection{Allocation of households to employment centres}

The number of households in the city $(N)$ is an important element in the determination of the equilibrium conditions. It is assumed that the city does not continue beyond the fringes of the residential areas. The total number of households in the city [given by equation (27)] is calculated as the integral of household density between the city fringes. The left $\left(f^{-}\right)$and right $\left(f^{+}\right)$fringes of the city are locations where 
the residential rent corresponding to the nearest node and the agricultural rent intersect. Solving equations (25) and (26) gives the locations of the fringes.

$$
\begin{aligned}
& \Psi_{1}\left(f^{-}, u\right)=R^{\mathrm{A}}, \\
& \Psi_{5}\left(f^{+}, u\right)=R^{\mathrm{A}}, \\
& N=\int_{f^{-}}^{f^{+}} \rho(r, u) \mathrm{d} r .
\end{aligned}
$$

In order to determine the number of households commuting to each of the centres, we also need to know the location at which households are indifferent between commuting to both centres. The middle node (which lies halfway between the two centres) plays an important role in determining the position of the indifference location. Households arriving at this node will commute by the fast mode to the centre whose wage rate was used to determine the artificial income corresponding of this node $\left(Y_{3}^{*}\right)$ [see equation (9)]. If this wage corresponds to centre 1 , the indifference location will be to the right of the middle node where the bid-rent curve corresponding to the middle node equals the bid-rent curve corresponding to centre 2 . On the other hand, if the wage corresponds to centre 2 the indifference location lies to the left of the middle node at a point where the bid-rent curve corresponding to the middle node crosses the bid-rent curve corresponding to centre $1 .{ }^{(4)}$ Thus, the indifference location $(f)$ can be given by:

$$
\left.\begin{array}{ll}
\Psi_{3}(f, u)=\Psi_{4}(f, u), & \text { if } w_{1}>w_{2}, \\
f=r_{3}, & \text { if } w_{1}=w_{2}, \\
\Psi_{3}(f, u)=\Psi_{2}(f, u), & \text { if } w_{1}<w_{2} .
\end{array}\right\}
$$

Given that $(f)$ is the indifference location between the centres, the number of households working in each centre is given by:

$$
\begin{aligned}
& N_{1}=\int_{f^{-}}^{f} \rho(r, u) \mathrm{d} r, \\
& N_{2}=\int_{f}^{f^{+}} \rho(r, u) \mathrm{d} r .
\end{aligned}
$$

\section{Alternative land markets}

In this section we analyze the implications of the behaviour of the households and firms as described in section 4 for two different institutional settings for the land market. We start with the usual assumption of a competitive land market followed by the case of a segmented land market where the government intervenes by imposing constraints on the size of the commercial areas.

\subsection{Competitive land market}

In this model we assume that households and firms bid against each other freely for land. At the edges of the centres the commercial and residential rents are equal. The competitive land bidding ensures that landlords will eventually extract the maximum saving that the consumers may enjoy, given the utility level. Because, by assumption,

(4) At times it can also happen that the wages of the two centres are the same. Households arriving at the middle node can travel to either of the two centres. This opens a possibility for crosscommuting. In such a situation, the expected number of households commuting to the centres will be distributed equally, leaving the position of the node to be an effective indifference location. 
Table 2. Equilibrium conditions.

Description

Equation

Previous equation reference

Equality of residential bid rent and commercial rent at the edges of employment centres

Cost-minimizing floor-space function at the centres

Zero-profit condition for production centres

Commercial land for centres

Number of households attending the centres

Left and right fringes of the linear city

Indifference location between the two centres

$$
\begin{aligned}
& \Psi_{2}\left(r_{2^{-}}, u\right)=\Psi_{2}\left(r_{2^{+}}, u\right)=R_{1}^{\mathrm{C}}, \\
& \Psi_{4}\left(r_{4^{-}}, u\right)=\Psi_{4}\left(r_{4^{+}}, u\right)=R_{2}^{\mathrm{C}} \\
& R_{1}^{\mathrm{F}}=r_{\mathrm{c}}^{\beta} \beta^{-\beta}(1-\beta)^{(\beta-1)} R_{1}^{\mathrm{C}(1-\beta)} \\
& R_{2}^{\mathrm{F}}=r_{\mathrm{c}}^{\beta} \beta^{-\beta}(1-\beta)^{(\beta-1)} R_{2}^{\mathrm{C}(1-\beta)} \\
& p P-E_{1}-w_{1}-R_{1}^{\mathrm{F}} a_{\mathrm{s}}=0 \\
& p P-E_{2}-w_{2}-R_{2}^{\mathrm{F}} a_{\mathrm{s}}=0 \\
& L_{1}=a_{\mathrm{s}} N_{1}\left[\frac{(1-\delta) r_{\mathrm{c}}}{\delta R_{1}^{\mathrm{C}}}\right]^{\delta} \\
& L_{2}=a_{\mathrm{s}} N_{2}\left[\frac{(1-\delta) r_{\mathrm{c}}}{\delta R_{2}^{\mathrm{C}}}\right]^{\delta} \\
& N_{1}=\int_{f^{-}}^{f} \rho(r, u) \mathrm{d} r \\
& N_{2}=\int_{f}^{f^{+}} \rho(r, u) \mathrm{d} r \\
& \Psi_{2}\left(f^{-}, u\right)=R^{\mathrm{A}} \\
& \Psi_{5}\left(f^{+}, u\right)=R^{\mathrm{A}} \\
& \Psi_{3}(f, u)=\Psi_{4}(f, u) \text { if } w_{1}>w_{2} \\
& f=r_{3} \quad \text { if } w_{1}=w_{2} \\
& \Psi_{3}(f, u)=\Psi_{2}(f, u) \text { if } w_{1}<w_{2}
\end{aligned}
$$

there are no transportation costs inside centres, the commercial rent curve assumes a uniform pattern. Centres situated at prespecified locations make no profit from production processes. The equilibrium conditions for the competitive land market are presented in table 2. Note that the system of thirteen equilibrium conditions has thirteen unknowns $\left\{R_{1}^{\mathrm{F}}, R_{2}^{\mathrm{F}}, w_{1}, w_{2}, R_{1}^{\mathrm{C}}, R_{2}^{\mathrm{C}}, f, f^{-}, f^{+}, N_{1}, N_{2}, L_{1}, L_{2}\right\}$. The numerical results for this model are presented in section 6 .

\subsection{A segmented land market}

In this land-market situation we impose a binding restriction on the commercial land area for one or both of the centres, such that $L_{i}=l^{\mathrm{R}}<L_{i}^{*}$, where $L_{i}^{*}$ is the land area occupied by centre $i$ if no restriction is imposed on it and $l^{\mathrm{R}}$ is a fixed amount of land reserved for commercial land use. As a result, the commercial land prices are higher than would be possible under the competitive land-market situation, because of the imposed scarcity. The restriction affects the commercial land rent, and the relative cost of land versus capital. Thus, at a centre with the commercial area restriction, the land rent is no longer determined by competitive bidding from residential land rent, but is instead based on the supply of commercial land. With a restricted supply of land, the commercial land rent increases, increasing the relative cost of land to capital in the centre. Leaving out the first two equations which are specially related to the competitive market case from table 2 above, the remaining eleven equations determine the 
equilibrium conditions for this model. The equilibrium condition in this market situation has eleven equations in eleven unknowns. The commercial land areas in the two centres, $L_{1}$ and $L_{2}$, are exogenous in this model.

\section{Model simulations, output, and discussion}

On the basis of the model above, we now present the simulation results for three transport-mode situations and three land-market regimes. With respect to the transport mode, we have looked at the unimodal case and two biomodal cases: partial and full bimodal. In the partial biomodal case, only centre 1 is served by the fast mode from two stations $\frac{1}{2} b$ miles away from its edges, in addition to the slow mode. On the other hand, in the full bimodal case, both centres are served by the fast mode from the prespecified stations, in addition to the slow mode. In each of the three levels of railway-transport investments we can have three situations concerning the land-market regimes in the centres. First, we can have competitive land-market conditions in both centres. Second, a segmented land market can be imposed in both centres. Finally, we assume a mixed land market in the city, with a combination of a competitive land market in one centre and a segmented land market in the other. As an extension of the model used by Sivitanidou and Wheaton (1992) our model uses the same values for some of the exogenous parameters that they used in their simulation. The remaining variables that relate to the extensions of the model are selected in a way that facilitates comparison. The values are given in table 3 . The graphical and numerical presentations of the simulation output are given in appendices A and B. In the following section we discuss the findings. In our model simulations we focus on two items: land-market distortions and investments in rail infrastructure.

Table 3. Value of exogenous parameters.

\begin{tabular}{lrlr}
\hline Parameter & Value & Parameter & Value \\
\hline Distance between nodes $\left(\frac{1}{2} b\right.$ miles) & 10.00 & National utility level $u$ & 1.20 \\
Width of the city (miles) & 1.00 & Price of nonland consumption & 1.00 \\
$\beta$ in utility function & 0.50 & Price of production output $(p)$ & 1.00 \\
Agricultural rent (\$ per acre) & 7500.00 & Productivity per worker $P$ & 22371 \\
Annual cost of transport & & Other production costs $\left(E_{1}\right)$ & 0 \\
$\quad$ slow mode $k_{\mathrm{s}}(\$)$ & 350.00 & Other production costs $\left(E_{2}\right)$ & 0 \\
$\quad$ fast mode $k_{\mathrm{f}}(\$)$ & 200.00 & Cost advantage $(A)$ for centre 1 $(\$)$ & 0 \\
$\delta$ in floor-space function & 0.77 & Commercial land restrictions & \\
Floor space per worker $a_{\mathrm{s}}\left(\mathrm{ft}^{2}\right)$ & 250.00 & centre 1 (square miles) & 1.80 \\
Annual rent of capital $\left(\$\right.$ per $\left.\mathrm{ft}^{2}\right) r_{\mathrm{c}}$ & 7.00 & centre 2 (square miles) & 1.80 \\
\hline
\end{tabular}

\subsection{Effect of land-market distortions}

The competitive land market makes it possible for the production centres to acquire the required amount of land input for their production process at the competitive land rent. This leaves unchanged the relative cost of land and capital, and the capital-toland ratio in the production technology of the centres. In contrast, in the segmented market, the limits on commercial land imposed in the centre(s) affect the commercial land rent and residential land rent. The restriction has a direct effect on the relative cost of capital and land. This in turn affects the wage-paying ability of the centres. The higher the commercial land restriction imposed on the centres, the higher the relative price of land to capital. Centres will then be increasingly capital intensive in their production processes. This leads to higher commercial land rents in the centres. In real life, this fact is visible in the form of high-rise buildings in central areas of cities. 
On the other hand, the commercial land restriction reduces the wage-paying ability of the centres. Thus, at each location, residential land rents will be lower than the corresponding locations under the competitive land-market situation.

As table B1 shows, the occurrence of restrictions on commercial land in the centres leads to an increase in total commercial land receipts $(0.277$ versus 0.273$)$ : the increase in rent per unit dominates the decrease in area. This seems to indicate that restrictions on commercial land use improve opportunities to use land rents as a source of finance for infrastructure. However, the increase in commercial land rents is more than offset by a decrease in residential land rents (3.758 versus 3.786 ).

\subsection{Effect of transportation investment}

The main focus of this paper is to determine the effect of investment in a fast mode on the urban economy. Given the open-city assumption, the transport investments lead to a growth of the urban economy in terms of more residents (workers), a higher residential density, and a higher production level. The decrease in transportation cost causes an increase in demand for residential land and the numéraire good. This initially leads to a higher utility level. However, the potential higher utility level causes an inflow of new households into the city until the utility level is again equal to the national utility level. For an analysis of the benefits of such investments our partial equilibrium model implies that welfare levels per household and profit levels remain unaffected in the long run. In a dynamic model an initial increase in profits and income disposable for other consumption may be expected, but these will be gradually dampened by the arrival of new residents and new producers. In the long run the only actor who will benefit is the absentee owner who receives higher rents. Therefore, we focus on the effects of transport investments on land prices.

To trace the effect of the transportation investment, we compare three cases: (1) the base case (the unimodal case); (2) the partial biomodal case, in which only one centre is served by the fast mode from the two stations; and (3) the complete biomodal case, in which the two centres are served by the fast mode from three stations. Investment in the fast transport mode makes commuting to the centres possible from a wider range of locations. Hence, the city size is enlarged by claiming land from agricultural use outside the city. In addition, the fast mode attracts denser residential settlements around the stations, which contributes to the population increase in the city. In general, the effect of the investment in fast transport has a different effect for the two land-market structures. In the competitive market the investment does not affect the wage-paying ability of the centres. However, the average residential land rents increase as a result of an increase in the density of settlement around the stations (compare the unimodal and complete biomodal cases in tables B1 and B2). On the other hand, because of the unchanged wage level, the commercial land rent is not affected. The capital-to-land ratio that represents the technology of the centres remains the same. However, the size of the centres increases due to the increase in the number of employees arriving at the centres. In the segmented market case, some effects occur on both the residential and the commercial sides. The additional employment induced by the fast mode has the same direction of effect on the residential and the commercial land rents in the city (as was discussed above). The important feature here is that, due to the increase in the demand of commercial land, coupled with the limited supply of land, the commercial land rent increases. This makes the nonlabour input into the production process costly. Hence, the wage-paying ability of the centres declines. As a result, the average residential land rent declines compared with the case of the competitive market (1.34 versus 1.36 ). 
We conclude from table B1 that, under a distorted land market, the total commercial rent increases in the city, as a result of the introduction of rail, is higher than in a competitive market $(0.302-0.273$ versus $0.314-0.277)$. However, total residential rents decrease substantially due to segmentation, and thus the net effect on total rent receipts is clearly less favourable under distorted land markets than under competitive land markets. Hence, if capturing rents as a means to finance infrastructure is feasible at all locations, the competitive market offers the best opportunities. But, if these opportunities are possible only at commercial locations, the conclusion may change.

\subsubsection{Competitive position of centres}

The effect of partial investment in the faster transport mode on the relative competitive position of the centres can be seen by allowing only one centre to benefit from such service. We can see this effect from tables B1 and B2 under the partial biomodal case. In the simulation, we allow a partial fast mode transport investment to serve only centre 1. In general, the fast mode leads to the growth of city size and an increase in total rent in both market situations. However, it affects the average and total rent of the individual centres differently. In the competitive market, the investment leads to the decline of average and total residential land rent around the disadvantaged centre. In this case, even though the average commercial land rent is not affected, the total commercial land rent of the centre declines. In contrast, in the segmented market case, the effect of the investment leads to a decline for both average and total commercial and residential land rents. This shows that the advantaged centre grows at the expense of the disadvantaged centre by claiming more of the households residing in the area between the centres.

\subsubsection{Land-rent loss or gain as a result of rail investment}

The railway investments lead to an increase in the total land rents. However, this does not imply a uniform increase of rent levels everywhere in the city. In fact, there are places which experience a decline of rent levels. This phenomenon occurs in the segmented land-market situation because investment in railway also affects the wage level in the centres by altering the relative price of land to capital. Residential land rent is directly affected by the wage-paying ability at the centres. Compared with the baseline unimodal case a partial railway investment leads to a wage increase in the centre which is not connected by rail and a decline in the wage level in the centre which is connected by rail. Thus, even though we observe an increase in the residential land-rent levels around the newly introduced railway stations and the centre which has experienced a wage increase, rent levels around the centre which has got a rail connection decline due to the decline in the wage level. As we further expand the railway system by connecting both centres by rail, we see a decrease in the wage level in the newly connected centre due to an increase in labour supply. On the other hand, the wage level in the centre which was previously connected by rail increases. This is because the supply of labour declines as a result of the commuting to the other centre made possible by the new rail investment. Thus, while residential land rent around the newly connected centre declines, the rent levels around the centre which was previously connected by rail increase. Reverse effects are observed on the commercial land rents. As labour supply in the centres increases due to the investment in rail, commercial land rent increases in the case of segmented markets with fixed land supply (see table B1).

\subsubsection{Effects of mixed land market}

We can also allow a mixed land market for the two centres in the city and see what effect this has. So we assume a competitive land market for centre 1 and a segmented land market for centre 2. The simulated result is given in table B2. Generally, as expected, 
the outcome lies between the outcomes of the two uniform land-market situations. In the unimodal and complete biomodal transport cases, alternating the land-market situation between centres results in perfect symmetry. However, the partial bimodal transport case has some special features. Higher land-rent receipts are achieved when the centre served by the railway has a competitive land market.

\section{Conclusion}

Generally, investment in the fast (rail) transport mode results in city growth, in terms of area size and population, an increase in rent receipts, and denser residential settlements. However, the effect of the investment for individual centres and their corresponding residential areas depends on the underlying land-market conditions. As one progressively invests in railways from a unimodal to a complete bimodal situation, one observes rent-losing and rent-gaining phenomena, along segments of the city in the segmented land-market situation.

When land rents are captured as a source of investment for railway infrastructure, the increase in total rents is highest in the competitive land-market situation. But it is important to realise that the rent increases are spread widely in the urban metropolitan area, which may make them difficult to collect in real-world situations. Of course, the most focused rent increases take place near the railway stations. Of special importance is the finding that, in the case of segmented markets, the total commercial rent receipts are higher than in a competitive land-market situation. Thus, as long as rent capturing is limited to commercial land use, the segmented land market is not as unfavourable as one might expect. The issue of land-market distortions is important because these distortions may have decisive impacts on long-run changes in transport demand in response to changes in the transport system. In the partial bimodal plan, connecting the centre under a competitive land market results in higher land-market receipts compared with connecting the centre with segmented land market.

In this paper we have analyzed the impact of a second transport mode on the dynamics of centres in a metropolitan area, under the assumption that the additional infrastructure may reinforce or weaken the existing commercial centres. However, transport investments may also have far-reaching effects on spatial structure, since they may stimulate the emergence of new centres. This theme of new centre formation has not been addressed in the present paper. Instead, we have focused explicitly on the demand for commercial land and the implications of distortions for the land market. Analyzing the possible emergence of additional centres falls outside the scope of this model, but is certainly a promising extension. In order to achieve this aim, the model should be developed in the direction of a more explicit treatment of production processes and agglomeration economies.

Acknowledgements. We acknowledge the financial support received from N.W.O. as well as from the TRANSUMO programme.

\section{References}

Anas A, Kim I, 1996, "General equilibrium models of polycentric urban land use with endogenous congestion and job agglomeration" Journal of Urban Economics 40232 - 256

Anas A, Arnott R, Small K, 1998, "Urban spatial structure” Journal of Economic Literature 36 $1426-1464$

Batten D F, 1995, "Network cities: creative urban agglomerations for the 21st century" Urban Economics 32 313-327

Clark C, 1958, "Transport-maker and breaker of cities" Town Planning Review 28 237-250

Clark W A V, Kuijpers-Linde M, 1994, "Commuting in restructuring urban regions" Urban Studies $31465-483$

Craig S G, Ng P T, 2001, "Using quantile smoothing splines to identify employment subcenters in a multicentric urban area" Journal of Urban Economics $\mathbf{4 9} 100-120$ 
Dieleman F M, Faludi A, 1998, "Randstad, Rhine-Ruhr and Flemish Diamond as one polynucleated macro-region" Tijdschrift voor Economische en Sociale Geografie 89320 - 327

Fujita M, 1989 Urban Economic Theory: Land Use and City Size (Cambridge University Press, Cambridge)

Fujita M, Krugman P, Venables A J, 1999 The Spatial Economy: Cities: Regions and International Trade (MIT Press, Cambridge, MA)

Garreau J, 1988 Edge City: Life on the New Frontier (Doubleday, New York)

Giulliano G, Small K A, 1991, "Subcenters in the Los Angeles region" Regional Science and Urban Economics 21163 - 182

Glaeser E L, Kahn M E, 2004, "Sprawl and urban growth", in Handbook of Urban and Regional Economics, Volume 4 (North-Holland, Amsterdam) pp $2481-2527$

McDonald J F, 1989, "Econometric studies of urban population density: a survey" Journal of Urban Economics 26361 - 385

McMillan D P, 2001, "Polycentric urban structure: the case of Milwaukee" Economic Perspectives $2515-27$

Modarres A, 2003, "Polycentricity and transit service" Transportation Research A 37841 -864

Musterd S, van Zelm I, 2001, "Polycentricity, household, and the identity of places" Urban Studies 38 679-696

Sivitanidou R, 1997, "Are center access advantages weakening? The case of office-commercial markets" Journal of Urban Economics $4279-97$

Sivitanidou R, Wheaton W C, 1992, "Wage and rent capitalization in the commercial real estate market" Journal of Urban Economics $31206-229$

van der Wusten, Faludi A, 1992, "The Randstad: playground for physical planners", in The Randstad: A Research and Policy Laboratory Eds F M Dieleman, S Musterd (Kluwer Academic, Dordrecht) pp $17-38$ 


\section{Appendix A}
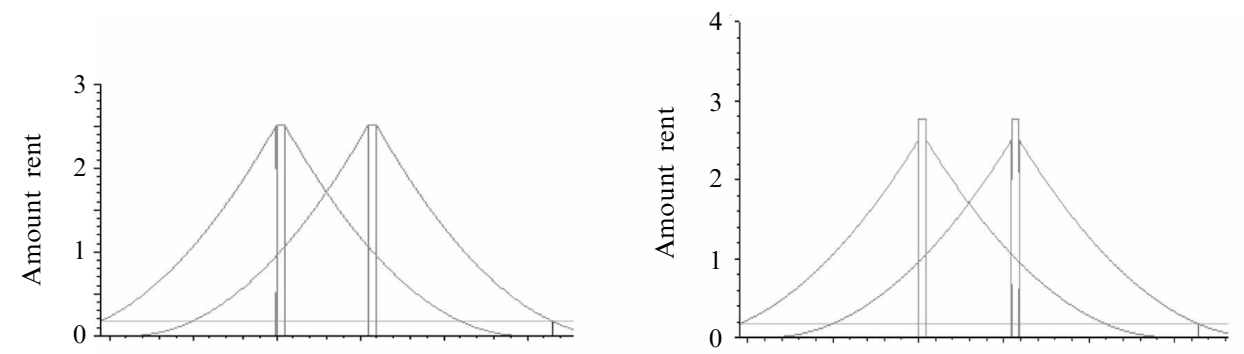

(a)
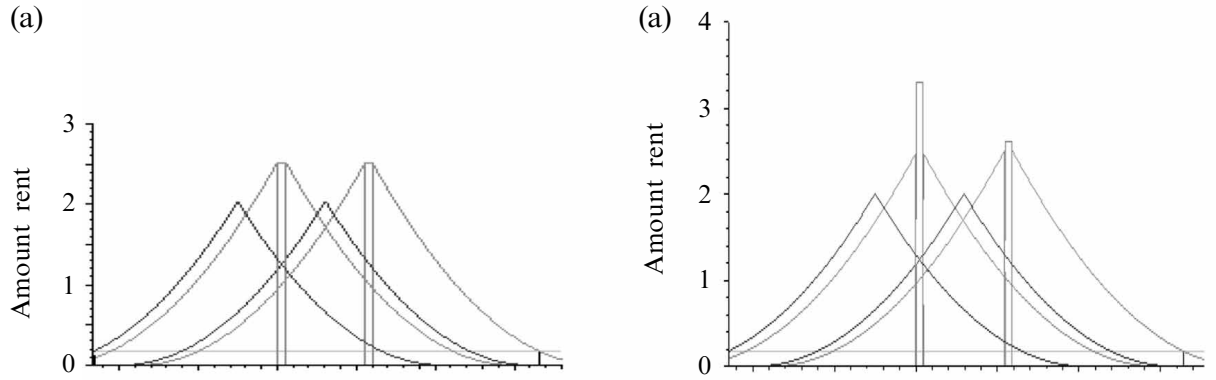

(b)
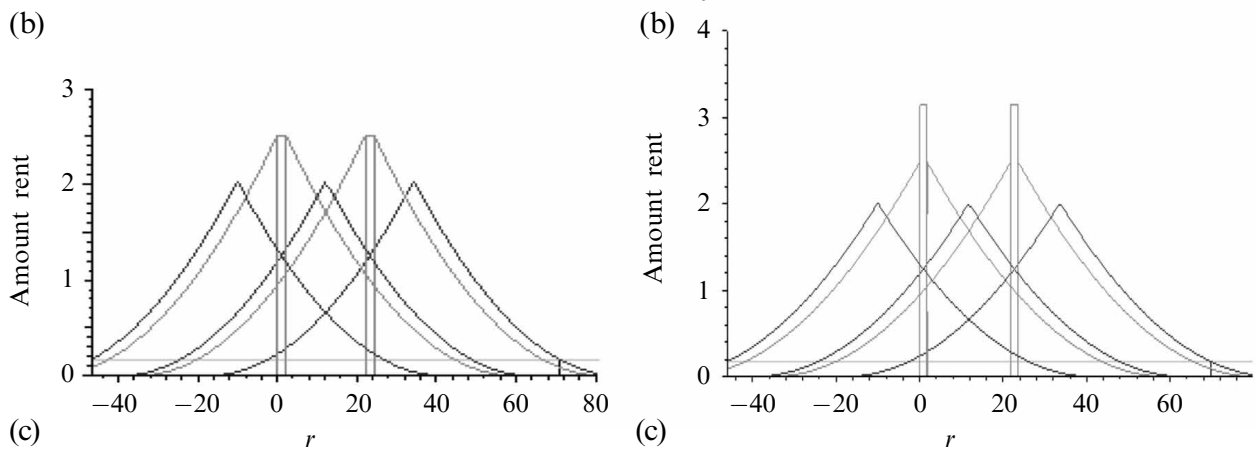

Figure A1. Competitive market, rent curves for (a) the unimodal - bicentric city case, (b) the partial bimodal bicentric city case, (c) the complete bimodal bicentric city case.

Figure A2. Segmented market, rents curves for (a) the unimodal-bicentric city case, (b) the partial bimodal bicentric city case, (c) the complete bimodal bicentric city case. 
Appendix B

Table B1. Simulation output for both markets.

\begin{tabular}{|c|c|c|c|c|c|c|c|c|c|c|c|c|c|c|c|c|}
\hline \multirow[t]{3}{*}{ Case } & \multirow[t]{3}{*}{ Centre } & \multirow{3}{*}{$\begin{array}{l}\text { Fast } \\
\text { mode }\end{array}$} & \multirow{2}{*}{\multicolumn{2}{|c|}{$\begin{array}{l}\text { Exogenous } \\
\text { parameters }\end{array}$}} & \multicolumn{12}{|c|}{ Endogenous variable } \\
\hline & & & & & \multirow[t]{2}{*}{3} & \multirow[t]{2}{*}{4} & \multirow[t]{2}{*}{5} & \multirow[t]{2}{*}{6} & \multirow[t]{2}{*}{7} & \multirow[t]{2}{*}{8} & \multirow[t]{2}{*}{9} & \multirow[t]{2}{*}{10} & \multirow[t]{2}{*}{11} & \multirow[t]{2}{*}{12} & \multirow[t]{2}{*}{13} & \multirow[t]{2}{*}{14} \\
\hline & & & 1 & 2 & & & & & & & & & & & & \\
\hline \multicolumn{17}{|l|}{ Unimodal } \\
\hline Competitive market & $\begin{array}{l}1 \\
2 \\
\text { Total/average }\end{array}$ & $\begin{array}{l}\text { no } \\
\text { no }\end{array}$ & & $\begin{array}{l}20000 \\
20000\end{array}$ & $\begin{array}{r}52.17 \\
52.17 \\
104.34\end{array}$ & $\begin{array}{l}250000 \\
250000 \\
500000\end{array}$ & $\begin{array}{l}1.95 \\
1.95 \\
3.90\end{array}$ & $\begin{array}{l}1.20 \\
1.20\end{array}$ & $\begin{array}{l}2.51 \\
2.51\end{array}$ & $\begin{array}{l}2.51 \\
2.51\end{array}$ & $\begin{array}{l}1.30 \\
1.30 \\
1.30\end{array}$ & $\begin{array}{l}2.51 \\
2.51 \\
2.51\end{array}$ & $\begin{array}{l}9.48 \\
9.48\end{array}$ & $\begin{array}{l}1.893 \\
1.893 \\
3.786\end{array}$ & $\begin{array}{l}0.136 \\
0.136 \\
0.273\end{array}$ & $\begin{array}{l}2.029 \\
2.029 \\
4.058\end{array}$ \\
\hline Segmented market & $\begin{array}{l}1 \\
2 \\
\text { Total/average }\end{array}$ & $\begin{array}{l}\text { no } \\
\text { no }\end{array}$ & $\begin{array}{l}1.80 \\
1.80\end{array}$ & $\begin{array}{l}19947 \\
19947\end{array}$ & $\begin{array}{r}52.02 \\
52.02 \\
104.04\end{array}$ & $\begin{array}{l}248751 \\
248751 \\
497502\end{array}$ & $\begin{array}{l}1.80 \\
1.80 \\
3.60\end{array}$ & $\begin{array}{l}1.32 \\
1.32\end{array}$ & $\begin{array}{l}2.50 \\
2.50\end{array}$ & $\begin{array}{l}2.77 \\
2.77\end{array}$ & $\begin{array}{l}1.30 \\
1.30 \\
1.30\end{array}$ & $\begin{array}{l}2.77 \\
2.77 \\
2.77\end{array}$ & $\begin{array}{l}9.70 \\
9.70\end{array}$ & $\begin{array}{l}1.879 \\
1.879 \\
3.758\end{array}$ & $\begin{array}{l}0.139 \\
0.139 \\
0.277\end{array}$ & $\begin{array}{l}2.018 \\
2.018 \\
4.035\end{array}$ \\
\hline \multicolumn{17}{|l|}{ Partial bimodal } \\
\hline Competitive market & $\begin{array}{l}1 \\
2 \\
\text { Total/average }\end{array}$ & $\begin{array}{l}\text { yes } \\
\text { no }\end{array}$ & & $\begin{array}{l}20000 \\
20000\end{array}$ & $\begin{array}{r}58.60 \\
50.03 \\
108.63\end{array}$ & $\begin{array}{l}290195 \\
237352 \\
527547\end{array}$ & $\begin{array}{l}2.26 \\
1.85 \\
4.11\end{array}$ & $\begin{array}{l}1.20 \\
1.20\end{array}$ & $\begin{array}{l}2.51 \\
2.51\end{array}$ & $\begin{array}{l}2.51 \\
2.51\end{array}$ & $\begin{array}{l}1.38 \\
1.28 \\
1.34\end{array}$ & $\begin{array}{l}2.51 \\
2.51 \\
2.51\end{array}$ & $\begin{array}{l}9.48 \\
9.48\end{array}$ & $\begin{array}{l}2.252 \\
1.786 \\
4.038\end{array}$ & $\begin{array}{l}0.158 \\
0.129 \\
0.288\end{array}$ & $\begin{array}{l}2.410 \\
1.916 \\
4.326\end{array}$ \\
\hline Segmented market & $\begin{array}{l}1 \\
2 \\
\text { Total/average }\end{array}$ & $\begin{array}{l}\text { yes } \\
\text { no }\end{array}$ & $\begin{array}{l}1.80 \\
1.80\end{array}$ & $\begin{array}{l}19846 \\
19979\end{array}$ & $\begin{array}{r}57.97 \\
50.16 \\
108.13\end{array}$ & $\begin{array}{l}285107 \\
238003 \\
523110\end{array}$ & $\begin{array}{l}1.80 \\
1.80 \\
3.60\end{array}$ & $\begin{array}{l}1.58 \\
1.25\end{array}$ & $\begin{array}{l}2.47 \\
2.51\end{array}$ & $\begin{array}{l}3.30 \\
2.61\end{array}$ & $\begin{array}{l}1.36 \\
1.28 \\
1.34\end{array}$ & $\begin{array}{l}3.30 \\
2.61 \\
2.99\end{array}$ & $\begin{array}{r}10.10 \\
9.57\end{array}$ & $\begin{array}{l}2.196 \\
1.791 \\
3.986\end{array}$ & $\begin{array}{l}0.166 \\
0.131 \\
0.297\end{array}$ & $\begin{array}{l}2.361 \\
1.922 \\
4.283\end{array}$ \\
\hline \multicolumn{17}{|l|}{ Complete bimodal } \\
\hline Competitive market & $\begin{array}{l}1 \\
2 \\
\text { Total/average }\end{array}$ & $\begin{array}{l}\text { yes } \\
\text { yes }\end{array}$ & & $\begin{array}{l}20000 \\
20000\end{array}$ & $\begin{array}{r}56.46 \\
56.46 \\
112.92\end{array}$ & $\begin{array}{l}275860 \\
275860 \\
551720\end{array}$ & $\begin{array}{l}2.15 \\
2.15 \\
4.30\end{array}$ & $\begin{array}{l}1.20 \\
1.20\end{array}$ & $\begin{array}{l}2.51 \\
2.51\end{array}$ & $\begin{array}{l}2.51 \\
2.51\end{array}$ & $\begin{array}{l}1.36 \\
1.36 \\
1.36\end{array}$ & $\begin{array}{l}2.51 \\
2.51 \\
2.51\end{array}$ & $\begin{array}{l}9.48 \\
9.48\end{array}$ & $\begin{array}{l}2.135 \\
2.135 \\
4.271\end{array}$ & $\begin{array}{l}0.151 \\
0.151 \\
0.302\end{array}$ & $\begin{array}{l}2.287 \\
2.287 \\
4.573\end{array}$ \\
\hline Segmented market & $\begin{array}{l}1 \\
2 \\
\text { Total/average }\end{array}$ & $\begin{array}{l}\text { yes } \\
\text { yes }\end{array}$ & $\begin{array}{l}1.80 \\
1.80\end{array}$ & $\begin{array}{l}19876 \\
19876\end{array}$ & $\begin{array}{r}56.10 \\
56.10 \\
112.21\end{array}$ & $\begin{array}{l}273894 \\
273894 \\
547788\end{array}$ & $\begin{array}{l}1.80 \\
1.80 \\
3.60\end{array}$ & $\begin{array}{l}1.50 \\
1.50\end{array}$ & $\begin{array}{l}2.48 \\
2.48\end{array}$ & $\begin{array}{l}3.14 \\
3.14\end{array}$ & $\begin{array}{l}1.34 \\
1.34 \\
1.34\end{array}$ & $\begin{array}{l}3.14 \\
3.14 \\
3.14\end{array}$ & $\begin{array}{l}9.98 \\
9.98\end{array}$ & $\begin{array}{l}2.100 \\
2.100 \\
4.199\end{array}$ & $\begin{array}{l}0.157 \\
0.157 \\
0.314\end{array}$ & $\begin{array}{l}2.257 \\
2.257 \\
4.514\end{array}$ \\
\hline
\end{tabular}

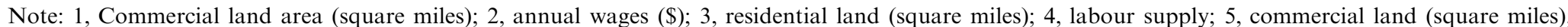

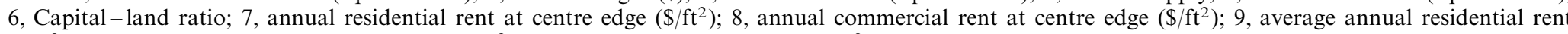

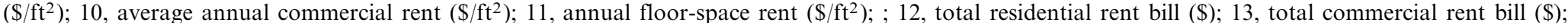
14 , total rent bill $(\$)$. 
Table B2. Simulation output for the three transport cases with a mixed land market between the centres.

\begin{tabular}{|c|c|c|c|c|c|c|c|c|c|c|c|c|c|c|c|c|}
\hline \multirow[t]{3}{*}{ Case } & \multirow[t]{3}{*}{ Centre } & \multirow{3}{*}{$\begin{array}{l}\text { Fast } \\
\text { mode }\end{array}$} & \multirow{2}{*}{\multicolumn{2}{|c|}{$\begin{array}{l}\text { Exogenous } \\
\text { parameters }\end{array}$}} & \multicolumn{12}{|c|}{ Endogenous variable } \\
\hline & & & & & \multirow[t]{2}{*}{3} & \multirow[t]{2}{*}{4} & \multirow[t]{2}{*}{5} & \multirow[t]{2}{*}{6} & \multirow[t]{2}{*}{7} & \multirow[t]{2}{*}{8} & \multirow[t]{2}{*}{9} & \multirow[t]{2}{*}{10} & \multirow[t]{2}{*}{11} & \multirow[t]{2}{*}{12} & \multirow[t]{2}{*}{13} & \multirow[t]{2}{*}{14} \\
\hline & & & 1 & 2 & & & & & & & & & & & & \\
\hline \multicolumn{17}{|l|}{ Unimodal } \\
\hline Competitive market & 1 & no & & 20000 & 52.17 & 250002 & 1.95 & 1.20 & 2.51 & 2.51 & 1.30 & 2.51 & 9.48 & 1.893 & 0.136 & 2.029 \\
\hline Segmented market & 2 & no & 1.80 & 19947 & 52.02 & 248751 & 1.80 & 1.32 & 2.50 & 2.77 & 1.31 & 2.77 & 9.70 & 1.879 & 0.139 & 2.018 \\
\hline & Total/average & & & & 104.19 & 498753 & 3.75 & & & & 1.31 & 2.64 & & 3.772 & 0.275 & 4.047 \\
\hline Segmented market & 1 & no & 1.80 & 19947 & 52.02 & 248752 & 1.80 & 1.32 & 2.50 & 2.77 & 1.30 & 2.77 & 9.70 & 1.879 & 0.139 & 2.018 \\
\hline Competitive market & 2 & no & & 20000 & 52.17 & 250001 & 1.95 & 1.20 & 2.51 & 2.51 & 1.29 & 2.51 & 9.48 & 1.893 & 0.136 & 2.029 \\
\hline & Total/average & & & & 104.19 & 498753 & 3.75 & & & & 1.30 & 2.64 & & 3.772 & 0.275 & 4.047 \\
\hline \multicolumn{17}{|l|}{ Partial biomodal } \\
\hline Competitive market & 1 & yes & & 20000 & 58.63 & 290350 & 2.26 & 1.20 & 2.51 & 2.51 & 1.38 & 2.51 & 9.48 & 2.253 & 0.158 & 2.412 \\
\hline Segmented market & 2 & no & 1.80 & 19982 & 49.95 & 236792 & 1.80 & 1.24 & 2.51 & 2.60 & 1.28 & 2.60 & 9.56 & 1.780 & 0.130 & 1.910 \\
\hline & Total/average & & & & 108.58 & 527142 & 4.06 & & & & 1.33 & 2.55 & & 4.034 & 0.288 & 4.322 \\
\hline Segmented market & 1 & yes & 1.80 & 19846 & 57.94 & 284938 & 1.80 & 1.58 & 2.47 & 3.30 & 1.36 & 3.30 & 10.10 & 2.194 & 0.165 & 2.360 \\
\hline Competitive market & 2 & no & & 20000 & 50.25 & 238674 & 1.86 & 1.20 & 2.51 & 2.51 & 1.29 & 2.51 & 9.48 & 1.798 & 0.130 & 1.928 \\
\hline & Total/average & & & & 108.19 & 523612 & 3.66 & & & & 1.33 & 2.90 & & 3.992 & 0.296 & 4.287 \\
\hline \multicolumn{17}{|l|}{ Complete bimodal } \\
\hline Competitive market & 1 & yes & & 20000 & 56.46 & 276985 & 2.16 & 1.20 & 2.51 & 2.51 & 1.34 & 2.51 & 9.48 & 2.249 & 0.151 & 2.400 \\
\hline \multirow[t]{2}{*}{ Segmented market } & 2 & yes & 1.80 & 19876 & 56.10 & 273985 & 1.80 & 1.50 & 2.48 & 3.14 & 1.35 & 3.14 & 9.98 & 1.985 & 0.157 & 2.142 \\
\hline & Total/average & & & & 112.56 & 550970 & 3.96 & & & & 1.34 & 2.80 & & 4.234 & 0.308 & 4.542 \\
\hline Segmented market & 1 & yes & 1.80 & 19876 & 56.10 & 273985 & 1.80 & 1.50 & 2.48 & 3.14 & 1.35 & 3.14 & 9.98 & 1.985 & 0.157 & 2.142 \\
\hline \multirow[t]{2}{*}{ Competitive market } & 2 & yes & & 20000 & 56.46 & 276985 & 2.16 & 1.20 & 2.51 & 2.51 & 1.34 & 2.51 & 9.48 & 2.249 & 0.151 & 2.400 \\
\hline & Total/average & & & & 112.56 & 550970 & 3.96 & & & & 1.34 & 2.80 & & 4.234 & 0.308 & 4.542 \\
\hline
\end{tabular}


Conditions of use. This article may be downloaded from the E\&P website for personal research by members of subscribing organisations. This PDF may not be placed on any website (or other online distribution system) without permission of the publisher. 